\title{
One possible way to treat a 76-years old patient with congenital heart disease and coronary artery disease
}

\author{
Ksenija Kapov Sviličić* \\ Clinic for Cardiovascular Diseases Magdalena, Krapinske Toplice, Croatia
}

This is a case study of 76-year old female patient with the congenital heart disease, discovered accidentally, after she started to complain of fatigue in a moderate effort.

After the initial echocardiography had been made, she was suspected to have (partial) atrioventricular canal defect. This is a form of endocardial cushion defect, infrequently en-countered in adults. According to literature, there are only few case reports describing occasional patients who survived into the sixth or seven decade of their life.
However, the patient was sent to our hospital then for undergoing a complete cardiac evaluation. At first, she was subjected to transthoracic and transoesophageal echocardiographic examination. The correct diagnosis was established (Figure 1 and 2). She had partial atrioventricular canal (PAVC) defect, known as a combination of primum atrial septal defect and a cleft in the anterior mitral leaflet, with a certain mitral insufficiency.

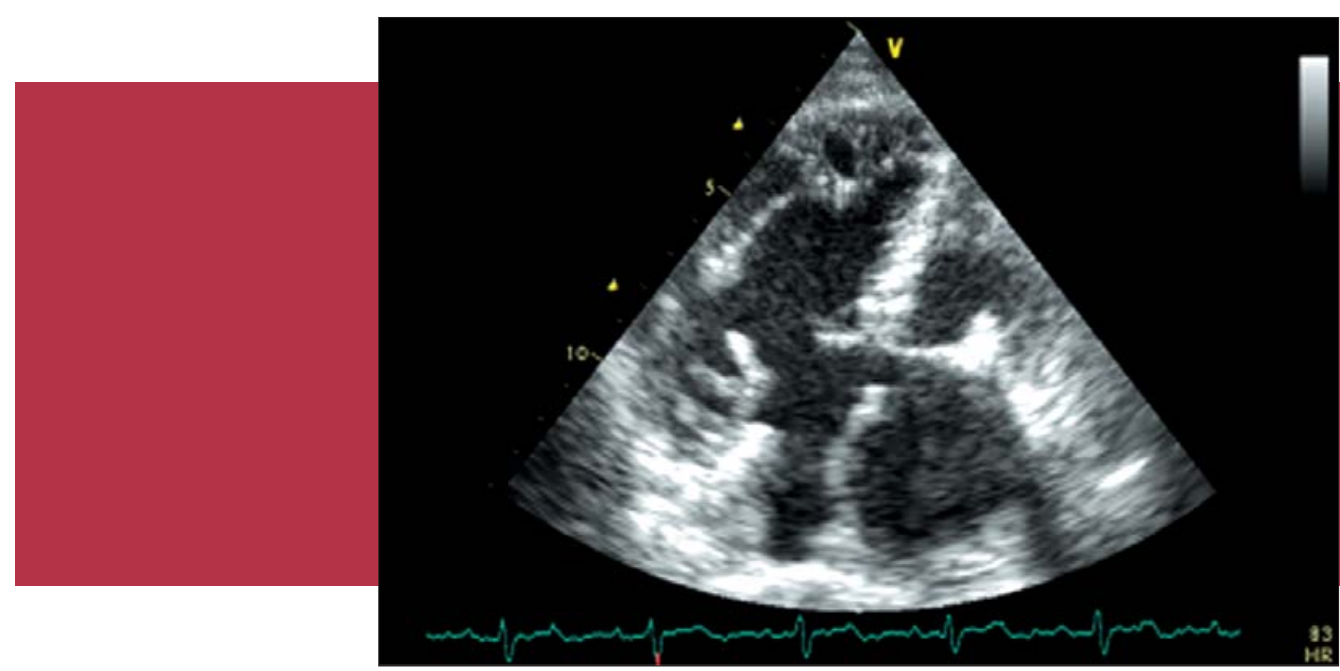

Figure 1. Transthoracic echocardiogram showing partial AV-canal defect (apical four chamber view).

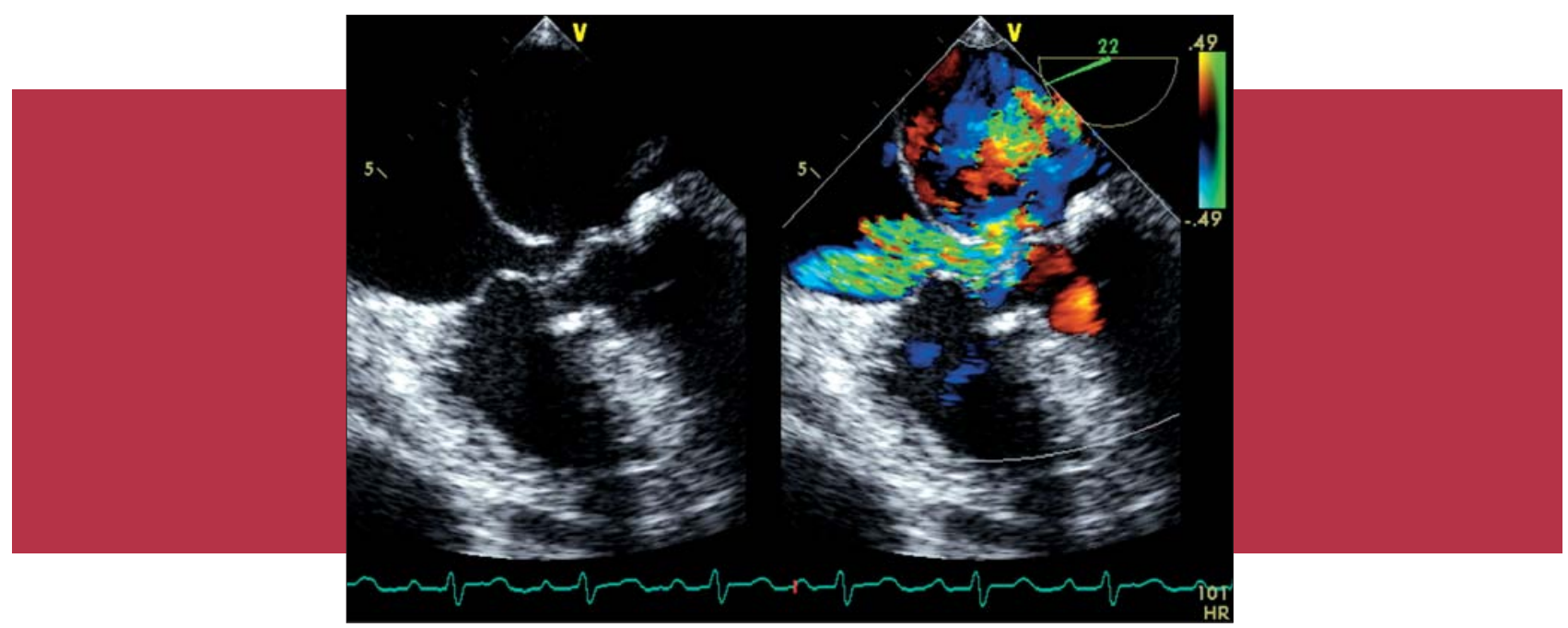

Figure 2. Transoesophageal echocardiogram showing partial AV-canal defect (A); the same transoesophageal (four chamber view) echocardiogram made with color flow Doppler (B). 
Nevertheless, we decided to perform cardiac catheterization, with hemodynamic findings as well. In short, our patient had preserved left ventricular systolic function, moderate mitral regurgitation and left-to-right shunting with the calculated ratio of measured pulmonary to systemic blood flow $2,29: 1,0$. However, we found out that she had coronary artery disease - a significant ostial right coronary artery stenosis.

What were we supposed to do then? She was 76-year old and she had been living her whole life without many symptoms. Were we supposed to perform a complex cardiac surgery or just to solve her (major) and acquired problem - to perform a percutaneous coronary intervention?

Finally, respecting our patient's wishes, as well as our "heart team" agreement, "only" percutaneous coronary intervention was indicated and performed.

The question arises: are we supposed to repair congenital heart disease in senior patients, who almost experience their life expectancy? Was our decision made according to present ESC Guidelines for the management of grown-up congenital heart disease? This is a true life-story with a few possible outcomes. This is a case report to be discussed, since there is evidence of the increasing population of adults with congenital cardiac malformation in our dayly practice.

KEYWORDS: partial atrioventricular canal in adults, congenital heart disease in adults, grown-up congenital heart disease.

\section{Received: $20^{\text {th }}$ Mar 2013}

*Address for correspondence: Magdalena - klinika za kardiovaskularne bolesti, Ljudevita Gaja 2, HR-49217 Krapinske Toplice, Croatia.

Phone: +385-49-244-444

E-mail: ksenija.kapov-svilicic@magdalena.hr

\section{Literature}

1. Minich LL, Atz AM, Colan SD, et al. Partial and transitional atrioventricular septal defect outcomes. Ann Thorac Surg. 2010;89:530-6.

2. Wiener L, Schneider PJ, Cox JW. Persistent cardiac ostium primum: a diagnostic dilemma in the aged. J Am Geriatr Soc. 1966;14:1156-62. 